\title{
BMJ Open Awareness regarding the adverse effect of tobacco among adults in India: findings from secondary data analysis of Global Adult Tobacco Survey
}

\author{
Ankita Kankaria, Soumya Swaroop Sahoo, Madhur Verma
}

To cite: Kankaria A, Sahoo SS, Verma M. Awareness regarding the adverse effect of tobacco among adults in India: findings from secondary data analysis of Global Adult Tobacco Survey. BMJ Open 2021;11:e044209. doi:10.1136/ bmjopen-2020-044209

- Prepublication history and additional supplemental material for this paper are available online. To view these files, please visit the journal online. To view these files, please visit the journal online (http://dx.doi org/10.1136/bmjopen-2020044209).

Received 31 August 2020 Accepted 17 June 2021

\section{Check for updates}

\section{(c) Author(s) (or their} employer(s)) 2021. Re-use permitted under CC BY-NC. No commercial re-use. See rights and permissions. Published by BMJ.

Department of Community \& Family Medicine, All India Institute of Medical Sciences Bathinda, Bathinda, Punjab, India

Correspondence to

Dr Madhur Verma

drmadhurverma@gmail.com

\section{ABSTRACT}

Objective To quantify the extent of awareness regarding the harmful effects of tobacco among the users (both smoked and smokeless) and non-users in India, and explore the determinants of comprehensive knowledge among the participants of the Global Adult Tobacco Survey (GATS), India.

Design Cross-sectional study.

Setting and participants The nationally representative GATS I (2009-2010) included 69296 participants using a multistage sampling method, while GATS II (2015-2016) interviewed 74037 respondents aged $>15$ years using a similar sampling method from all the states and union territories in India.

\section{Primary and secondary outcome}

measures Comprehensive score were derived from nine items that explored awareness regarding the adverse effects of tobacco use among both users and non-users of tobacco in GATS II. Secondary outcome included predictors of awareness regarding adverse effects of tobacco and changes in the awareness compared with the previous round of the survey.

Results About $60.2 \%, 57.5 \%$ and $66.5 \%$ of the smokers, smokeless tobacco (SLT) users and non-users were aware of the adverse effects of tobacco, respectively. The awareness depicted significant age, gender, marital status, education status, urban-rural, wealth and regional disparities $(p<0.05)$. Intention to quit tobacco use also varied significantly with awareness. Among smokers, awareness was high in those residing in eastern India and the poorest participants. Among SLT users, awareness was more among male participants, those who were poorest and lived in western India. Among non-users, awareness was more among middle-aged, more educated, rich participants of west India. Compared with GATS I, an increase in awareness was observed in GATS II across gender, age groups, residential areas and geographical regions in India.

Conclusions Comprehensive awareness of tobacco's harmful effects is far from desirable among Indian users. We recommend further customised health promotion campaigns to counter the regional disparities, adopt a gender-neutral approach and target adolescents.

\section{INTRODUCTION}

Tobacco is the single most preventable cause of premature death and risk factor for major
Strengths and limitations of this study

- One of the very first comprehensive assessments of the awareness regarding the adverse effects of tobacco from the second round of the Global Adult Tobacco Survey India (2016-2017).

- We estimated the predictors of adequate awareness through a weighted analysis that highlighted feasible, actionable points.

- We have analysed large and nationally representative data on tobacco use from India.

- Appropriate sampling during the survey makes the results generalisable, and other lower middleincome countries can adopt recommendations.

- Lack of a uniform tool to assess awareness across two rounds of the survey was the critical limitation of the study that can lead to underestimation of the changes in the understanding across two rounds of the survey.

non-communicable diseases. ${ }^{1}$ Tobacco usage causes more than 8 million deaths per year, with 7 million of these attributable to direct tobacco use. Moreover, the fact that $80 \%$ of the world's 1.3 billion tobacco users live in low/middle-income countries (LMICs) is a matter of concern. ${ }^{2}$

There has been a sustained increase in tobacco consumption in LMICs, which are on the target of tobacco manufacturers for newer markets. ${ }^{34}$ The tobacco epidemic is steadily on the rise, affecting LMICs due to a lack of awareness in the population, insufficient health infrastructure and weak regulatory interventions. ${ }^{5}$ India is home to 275 million tobacco users and is second only to China in tobacco products. ${ }^{6}$ In India, tobacco is responsible for one-tenth ( 1 million) of all the deaths each year and a significant burden of cancer cases ( $45 \%$ of male's cancer and $20 \%$ of female's cancer).$^{78}$ India displays a diverse pattern of tobacco consumption, in smoked form as cigarettes and bidis and smokeless forms like khaini, pan and gutkha. In India, 
almost $50 \%$ of the users use smokeless tobacco (SLT), followed by smoking and dual-use. ${ }^{9}$ SLT use, constituting tobacco products consumed without burning through the mouth or nose, is widely prevalent in India, accounting for $74 \%$ of the global burden of SLT. ${ }^{10}$

Despite sustained efforts by the government, tobacco consumption is still a growing public health concern. Tobacco is not merely a sociocultural problem but multifaceted with economic, biomedical and geopolitical aspects in many parts of India. Also, a matter of concern is the increasing use of tobacco products in adolescents, young adults and women, particularly more active age groups. In this context, tobacco control policies need to be implemented with interventions adapted to the local environment. The WHO also recommends surveillance, research and an informal approach that promotes the exchange of information and knowledge to increase awareness within the broad framework for addressing tobacco dependence. ${ }^{11}$ According to the Global Adult Tobacco Survey (GATS) 2016-2017, in India, 92\% of adults believe that smoking causes severe illnesses, and $96 \%$ believe that SLT can cause serious illness. ${ }^{12}$ The government of India launched the National Tobacco Control Program in 2007-2008. One of the programme's primary objectives was public awareness/mass media campaigns for awareness building and behaviour change. Despite sustained efforts, awareness has not been on expected trends. Furthermore, studies from other LMICs have demonstrated that an increase in levels of awareness has not continually transformed into desirable quit rates. This disconnect between awareness and quit rates would provide new targets for devising more focused public health education campaigns. ${ }^{13} 14$ In India, with varied demographics of tobacco use, monitoring, raising awareness, and realising tobacco control policy achievements are instrumental in halting the tobacco epidemic.

Since enforcing legislation alone cannot bring the desired changes, we need to see the population response and behaviour change towards this public health problem. The legislations need to be supplemented by adequate awareness, health education and communication at the population level. Awareness forms an integral part of health literacy and the first step for behaviour modification. It provides a dual benefit of motivating users to contemplate and quit smoking and dissuading non-smokers from adopting this habit. ${ }^{15}{ }^{16}$ Dissemination of facts regarding the harmful effects of tobacco has been recognised as an essential tool in this context. Also, it encourages people to adhere to tobacco legislation, smoking bans and understand the perceived threats of first and secondhand smoke on their lives, family and the community. Studies in LMICs using the GATS framework have outlined that lower levels of education, rural population and current smokers were likely to be less aware of the harmful effects of tobacco and secondhand smoke. ${ }^{17}$ Similar findings have been documented in populationbased surveys in Vietnam and Mongolia. ${ }^{18} 19$ In India, existing literature suggests that gender, age, ethnicity, education, income and smoking status are associated with awareness of the harmful effects of smoking. ${ }^{20-22}$ As awareness contributes to a more considerable extent to behaviour modification and tobacco cessation practices, it needs to be studied in entirety concerning socioeconomic and regional distributions to get a clear view on this aspect. Within this context, we examined the awareness regarding the harmful effects of tobacco among the users (both smoked and smokeless) and non-users based on the secondary data analysis of GATS 2016-2017 and compared it with GATS 2009-2010. Our primary objective was to study the awareness regarding harmful effects of tobacco among the users (smokers and SLT users) and non-users. The secondary objectives were to examine the factors affecting the awareness among these groups and compare the quantum of change in awareness regarding harmful effects of tobacco between the two rounds of GATS India (GATS I and GATS II) among users and nonusers of tobacco.

\section{METHODOLOGY}

In this study, we used nationally representative data of GATS-I (2009-2010) and GATS-II (2016-2017) in India. ${ }^{12}$ GATS is a cross-sectional household-based survey conducted among a population aged 15 years and above, using a global standardised methodology to collect tobacco-related information. ${ }^{123}$ The survey gathers information regarding the respondents' background characteristics, tobacco use (smoking and smokeless) patterns, cessation, secondhand smoke exposure, economics, media, knowledge, attitudes and perceptions of tobacco use.

We have used GATS-I figures as the baseline to quantify the change in the awareness regarding harmful effects in the recent GATS-II survey data. The GATS-II survey included 74037 participants, and the response rate was $99.9 \%$. The dependent variable was awareness regarding the harmful effects of smoking and SLT. The GATS-I survey included 69296 participants, and the response rate was $96.8 \%$.

\section{Operational definitions}

We defined our variables as per the publicly available codebooks for GATS I and II. ${ }^{24} 25$

- Tobacco smokers: The information regarding tobacco users was obtained from the following questions 'Do you currently smoke tobacco?' Those who smoked 'Daily' or 'Less than daily' were considered tobacco smokers.

- SLT users: The information regarding SLT users was obtained from the following questions 'Do you currently use smokeless tobacco?'. Those who smoked Daily or Less than daily were considered tobacco smokers.

- Non-users: Those who said not all for both questions mentioned above were considered as non-users. 
- Awareness regarding the harmful effect of tobacco: For GATS 2017, this information was obtained from the following questions:

i. 'Based on what you know or believe, does smoking tobacco cause serious illness?'

ii. 'Based on what you know or believe, does smoking tobacco cause stroke?'

iii. 'Based on what you know or believe, does smoking tobacco cause heart attack?'

iv. 'Based on what you know or believe, does smoking tobacco cause lung cancer?'

v. 'Based on what you know or believe, does smoking tobacco cause chronic cough?'

vi. 'Based on what you know or believe, using smokeless tobacco cause serious illness?'

vii. 'Based on what you know or believe, use of smokeless tobacco cause oral cancer?'

viii. 'Based on what you know or believe, use of smokeless tobacco cause dental disease?'

ix. 'Based on what you know or believe, does using smokeless tobacco during pregnancy cause harm to a fetus?'

In comparison to GATS 2017, only five questions (out of nine items mentioned above) on awareness regarding the harmful effect of tobacco were included in the GATS 2010. For comparison between GATS I and GATS II, the following five common variables were included in the analysis:

i. 'Based on what you know or believe, does smoking tobacco cause serious illness?',

ii. 'Based on what you know or believe, does smoking tobacco cause stroke?',

iii. 'Based on what you know or believe, does smoking tobacco cause heart attack?',

iv. 'Based on what you know or believe, does smoking tobacco cause lung cancer?'

v. 'Based on what you know or believe, using smokeless tobacco cause serious illness?' Those who responded 'Yes' to all the questions were considered as aware. Responses other than Yes were viewed as being unaware and included 'No' and 'Don't Know'.

\section{Ethical consideration}

This being a secondary data analysis, we applied for an expedited waiver from the institutional ethics board. The manuscript was prepared following the Strengthening the Reporting of Observational Studiesin Epidemiology guidelines (online supplemental file 1).

\section{Data analysis}

All the estimates in this article are based on the weighted sample, and the numbers are unweighted. Complex sample analysis of the data was carried out using SPSS for Windows V.17.0, Released 2008 (SPSS) after taking stratification, clustering and sampling weights into account. The background characteristics of the study participants were presented as point estimates (\%) with 95\% CI. The awareness of tobacco's harmful effects was assessed among smokers, SLT users and non-users. We performed bivariate analysis to determine the statistical significance across selected study variables. Logistic regression analysis was done to identify the predictors of awareness regarding the harmful effects of tobacco use among the respondents. All the significant independent variables on bivariate logistic regression (unadjusted OR: $\mathrm{p}<0.2$ ) were used to build the final multiple logistic regression model to highlight the predictor variables (adjusted OR: $p<0.05$ ) that were associated with awareness. The independent variables were age, gender, marital status, residence, education, region and wealth index. For calculating the wealth index, a score between 0 and 10 was calculated from 10 household assets. These scores were divided into five parts based on their distribution, and households were categorised. The relative proportional changes in the awareness between the two rounds of GATS India were calculated (Relative Change $=($ GATS II - GATS I)/ GATS I* $100 \%$ ) to depict the trends among the tobacco users as compared with the non-users. For calculating the difference, we used only the common questions (five items) to both the rounds.

\section{RESULTS}

\section{Background characteristics of the study participants}

In GATS-I, there were 69296 participants, and among them, $14 \%$ (11 596) were smokers, 25.9\% (16 812) were SLT users, and $64.9 \%$ (44 967) were non-tobacco users. In GATS 2017, of the 74037 participants, $10.7 \%$ (9499) were smokers, $24.1 \%$ (15 235) were SLT users and 78.6\% (52 $180)$ were non-users of tobacco. The background characteristics of tobacco users and non-users from GATS-I and II are presented in table 1 .

\section{Awareness regarding the adverse effects of tobacco among the participants of the GATS II}

Table 2 depicts the awareness regarding the harmful effects of tobacco in three groups-smokers, SLT users and non-tobacco users as per the GATS-II. About $60.2 \%$ (5826) smokers and $57.5 \%$ (8933) SLT users were aware of tobacco's adverse effects. High levels of awareness $(\mathrm{p}<0.05)$ was observed among male participants, and those who were married, young (15-29 years), educated beyond secondary schools, urban residents, in the third percentile of wealth index and who had positive intentions to quit tobacco use. The only difference was observed in regions where smokers from eastern India were more aware, and awareness was high among SLT users from western India. Among non-users, 66.5\% (35 818) were aware of the harmful effects of smoking. The awareness was high $(\mathrm{p}<0.05)$ among men, unmarried, aged 30-44 years, educated beyond secondary schools, urban residents, residing in North India and the first percentile of wealth index.

Factors affecting the awareness regarding the adverse effects of tobacco among GATS II participants

Among the smokers, SLT users and non-users, bivariate analysis depicted higher odds of having awareness regarding the 


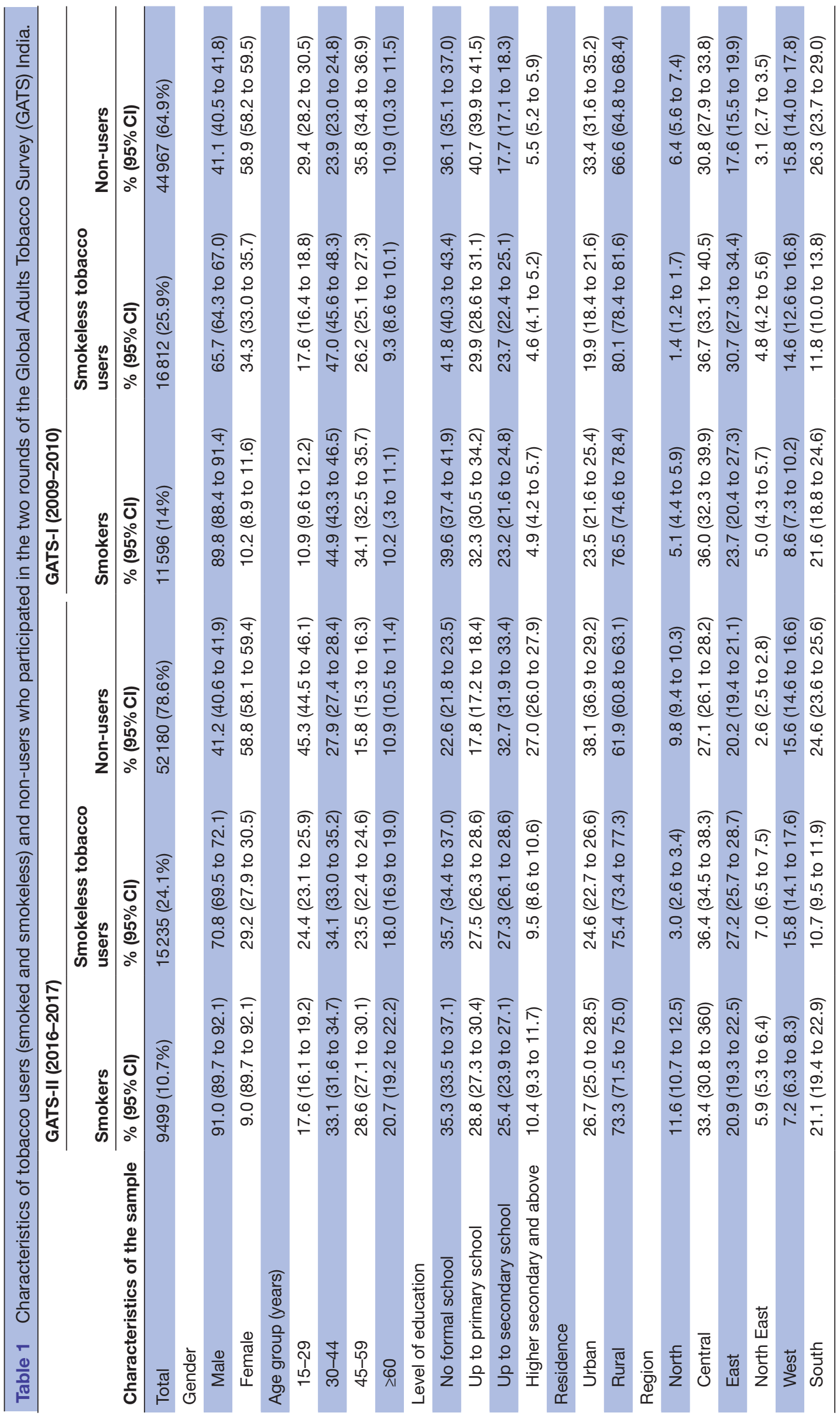


Table 2 Awareness regarding adverse effects due to tobacco use among the participants of the Global Adults Tobacco Survey (India)-round II (2016-2017) ( $\mathrm{N}=74025)$

\begin{tabular}{|c|c|c|c|c|c|c|}
\hline \multirow[t]{2}{*}{ Characteristics } & \multicolumn{2}{|l|}{$\begin{array}{l}\text { Smokers } \\
(\mathrm{n}=9499)\end{array}$} & \multicolumn{2}{|c|}{$\begin{array}{l}\text { Smokeless tobacco-users } \\
(n=15235)\end{array}$} & \multicolumn{2}{|l|}{$\begin{array}{l}\text { Non-users } \\
(n=52180)\end{array}$} \\
\hline & $\begin{array}{l}\text { Weighted \% } \\
\text { (95\% Cl) }\end{array}$ & $P$ value & $\begin{array}{l}\text { Weighted \% } \\
(95 \% \mathrm{Cl})\end{array}$ & $P$ value & Weighted \% (95\% Cl) & $P$ value \\
\hline \multirow[t]{2}{*}{ Overall awareness } & $n=5826$ & & $n=8933$ & & $\mathrm{n}=35818$ & \\
\hline & 60.2 (58.2 to 62.3$)$ & & 57.2 (55.8 to 59.2$)$ & & 66.5 (65.5 to 67.5$)$ & \\
\hline \multicolumn{7}{|l|}{ Gender } \\
\hline Female & $43.0(36.7$ to 49.6$)$ & & $50.6(48.0$ to 53.1$)$ & & 64.7 (63.5 to 65.9$)$ & \\
\hline \multicolumn{7}{|l|}{ Marital status } \\
\hline Unmarried & $59.3(52.1$ to 66.1$)$ & 0.013 & 54.2 (48.7 to 59.5$)$ & & 67.5 (65.8 to 69.1$)$ & 0.000 \\
\hline Married & 61.1 (59.1 to 63.2$)$ & & 58.9 (57.2 to 60.6$)$ & & 66.8 (65.8 to 67.9$)$ & \\
\hline $30-44$ & $62.1(59.1$ to 65.0$)$ & & 58.9 (56.6 to 61.1$)$ & & 68.5 (67.2 to 69.8$)$ & \\
\hline $45-59$ & 60.7 (57.7 to 63.7$)$ & & 59.1 (56.4 to 61.7$)$ & & 66.6 (64.9 to 68.2$)$ & \\
\hline$\geq 60$ & 54.1 (50.3. to 57.9$)$ & & 52.6 (49.5 to 55.8$)$ & & 59.2 (57.3 to 61.1$)$ & \\
\hline \multicolumn{7}{|l|}{ Level of education } \\
\hline No formal school & 51.6 (48.6 to 54.7$)$ & 0.000 & 48.6 (46.1 to 51.1$)$ & 0.000 & 55.5 (53.8 to 57.1$)$ & 0.000 \\
\hline Up to primary school & 60.2 (57.0 to 63.2$)$ & & 57.8 (55.2 to 60.3$)$ & & 64.6 (62.9 to 66.2$)$ & \\
\hline Up to secondary school & 66.8 (63.3 to 70.2$)$ & & $64.6(61.6$ to 67.5$)$ & & 68.1 (66.7 to 69.5$)$ & \\
\hline Higher secondary and above & 73.6 (68.0 to 78.6$)$ & & $69.9(65.1$ to 74.4$)$ & & 75.2 (73.8 to 76.7$)$ & \\
\hline \multicolumn{7}{|l|}{ Residence } \\
\hline North East & $53.8(49.4$ to 58.1$)$ & & 53.6 (50.6 to 56.6$)$ & & 54.3 (51.3 to 57.3$)$ & \\
\hline West & 54.4 (46.3 to 62.4$)$ & & 66.1 (61.7 to 70.2$)$ & & 71.5 (68.9 to 74.0$)$ & \\
\hline South & 61.5 (57.3 to 65.5$)$ & & 46.2 (41.2 to 51.3$)$ & & $68.3(66.4$ to 70.1$)$ & \\
\hline \multicolumn{7}{|l|}{ Wealth-index quintiles } \\
\hline First & 66.3 (60.3 to 71.8$)$ & 0.000 & 67.1 (61.5 to 72.3 ) & 0.000 & 72.2 (70.3 to 74.1$)$ & 0.000 \\
\hline Second & 64.2 (59.9 to 68.3$)$ & & 63.1 (58.9 to 67.1$)$ & & 69.9 (68.2 to 71.5$)$ & \\
\hline Third & 66.0 (61.0 to 70.7$)$ & & 64.1 (60.4 to67.6) & & 67.5 (65.6 to 69.3$)$ & \\
\hline Fourth & 61.1 (57.8 to 64.3$)$ & & 57.2 (54.7 to 59.7$)$ & & $66.0(64.4$ to 67.6$)$ & \\
\hline Fifth & 52 (48.5 to 55.5) & & 50.8 (48.2 to 53.4 ) & & 56.9 (54.9 to 58.9$)$ & \\
\hline \multicolumn{7}{|l|}{ Intention to quit tobacco use } \\
\hline Yes & 64.0 (60.7 to 68) & 0.001 & 59.7 (57.2 to 62.2$)$ & 0.009 & NA & \\
\hline No & 58.1 (55.8 to 60.5$)$ & & 56.5 (54.6 to 58.4$)$ & & NA & \\
\hline
\end{tabular}

harmful effects of using tobacco among men, educated beyond secondary school, residing in western India and belonging to low wealth index compared with their respective reference groups. Additionally, awareness was high among smokers and non-users who were unmarried and aged 30-44 years, whereas, among SLT users, awareness was more among those who were married and aged $45-59$ years.

Subsequently, multiple logistic regression depicted higher chances of having awareness among participants 
who were educated beyond secondary school, belong to the third percentile in wealth index, and intend to quit tobacco use in the last 12 months. Additionally, after adjustment, awareness among smokers was high in those residing in eastern India and belonging to the wealth index's first percentile. Among SLT users, awareness was more among male participants, those who belong to the first percentile of wealth index and those residing in western India (table 3). Among non-users, after adjustment, awareness was more among participants aged 30-44 years, educated beyond secondary school, residing in western India and who belong to the fourth percentile of wealth index.

\section{Changes in the awareness regarding adverse effects of tobacco between two rounds of GATS}

We estimated the changes in awareness patterns about tobacco use over the years by comparing it across two surveys of the GATS India (table 4). They were asked regarding their awareness of the harmful effects of tobacco. During GATS-I, 38\% of smokers (4930) and $38.9 \%$ (6961) of SLT users were aware of tobacco's adverse effects (figure 1). We observed increased awareness during the second round of GATS-II from the GATS-I among both smokers and SLT users. The increase in awareness was observed across gender, different age groups, residential areas and regions in India. Among smokers, an expansion beyond $50 \%$ was observed among men, across all ages, both in the rural and urban areas and in Northern, Southern and Western India. Among SLT users, an increase beyond $50 \%$ was observed in $\geq 45$ years, in rural residents and western India. Among nonusers, more than $50 \%$ increase in awareness was observed only among participants residing in west India.

\section{DISCUSSION}

This study explored the awareness of tobacco's harmful effects among its current users and non-users in India using a nationally representative survey dataset. Our study observed that $60 \%$ and $57 \%$ of the current users of smoked and SLT were aware of its harmful effects, respectively. This was lower than the knowledge levels observed in the non-smokers. This can be attributed to concerted efforts made by the government through public health campaigns. However, awareness about adverse effects has increased in GATS-II compared with round I; there is still a need for consistent efforts to improve it further. Also, the difference in awareness levels of tobacco users and non-users highlights the challenges of the one-size-fits-all approach in terms of awareness generation.

We observed significant disparities in awareness across different sociodemographic characteristics. Our study depicted better awareness among the men regarding the harmful effects of smoked and SLT compared with women. This can be due to the higher use of tobacco among men and their peers. Men have easy access to shops that sell tobacco products, and warnings on these cigarette packets/SLT pouches increase awareness. ${ }^{26}$ On the other hand, advertisements over television in movie halls help create awareness across genders and a wider age group. However, previous studies have demonstrated country-specific variations in harmful perception by gender. ${ }^{20-22}{ }^{27}$ In a study by Gupta and Kumar, $91.5 \%$ of men and $88.5 \%$ of women were aware that smoking causes serious illness. ${ }^{28}$ Nevertheless, this disparity is a severe cause of concern and highlights the need to improve awareness about the harmful effect of smoking through a gender-neutral approach. Women usually perceive the risk of dying from smoking significantly higher than men and can influence the smoking behaviours of the men in their family. ${ }^{29}$ One of the strategies can be the inclusion of women and family in social media advertisement or broadcasts. Awareness decreased with an increase in the age of the respondents. The reason can be their ageold belief that tobacco usage is not a serious issue as they have seen people around them without any health issue or being chronic tobacco users make them less receptive to any advice that concerns quitting. Previous studies have also depicted a decrease in intention to quit with increasing age. ${ }^{30}{ }^{31}$ Hence, they should be informed that quitting tobacco at any age leads to immediate health benefits, such as reduced stroke risks, cardiovascular disease and tobacco-related cancers. ${ }^{31}$

Awareness was directly related to the number of years spent in school and was low among illiterate respondents. Previous studies corroborate the causal association between education levels and the smoking status of the individual. ${ }^{32-34}$ Therefore, we require prevention strategies that focus on the formative years of life and modify the factors that influence tobacco usage (smoke and smokeless) in the later stages. Like other studies, low awareness regarding the adverse effects of tobacco was observed in respondents belonging to the lowest wealth quintile. $^{162730}$

A relative increase in awareness was observed among rural residents in GATS-II, but it remained lower than that of the urban area. The rural population is the most vulnerable, and more inclination toward tobacco consumption and quit attempts are less likely to be successful. This could be mainly due to reduced community support for quitting and less motivation to quit and stabilise addictive behaviour with socio-cultural traditions. Most of the time, they do not complete pharmaceutical and behavioural intervention for tobacco quitting because of the lack of self-motivation or medical avenues for quitting. This is further compounded by poor access to drug deaddictioncentres and a lack of stringent implementation of tobacco control measures in rural areas. ${ }^{5}$ To overcome the ruralurban disparities and give an impetus to the awareness campaign in rural areas, the Panchayati Raj institutions can provide a platform for awareness campaigns with active participation by local bodies like the Sarpanch and village elderly. Furthermore, the primary healthcare centres can function as the first point of contact for advice and treatment of tobacco addiction by providing 


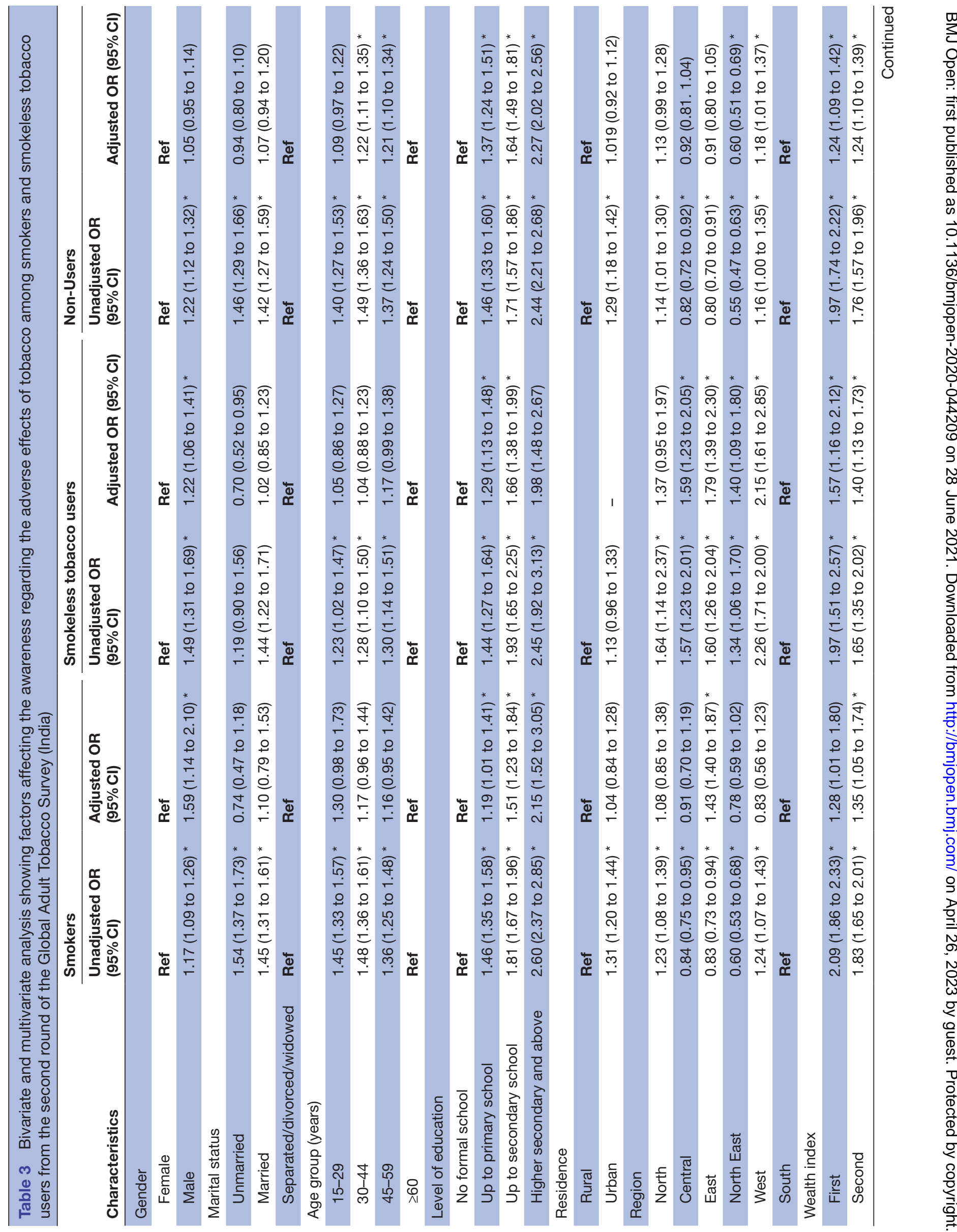




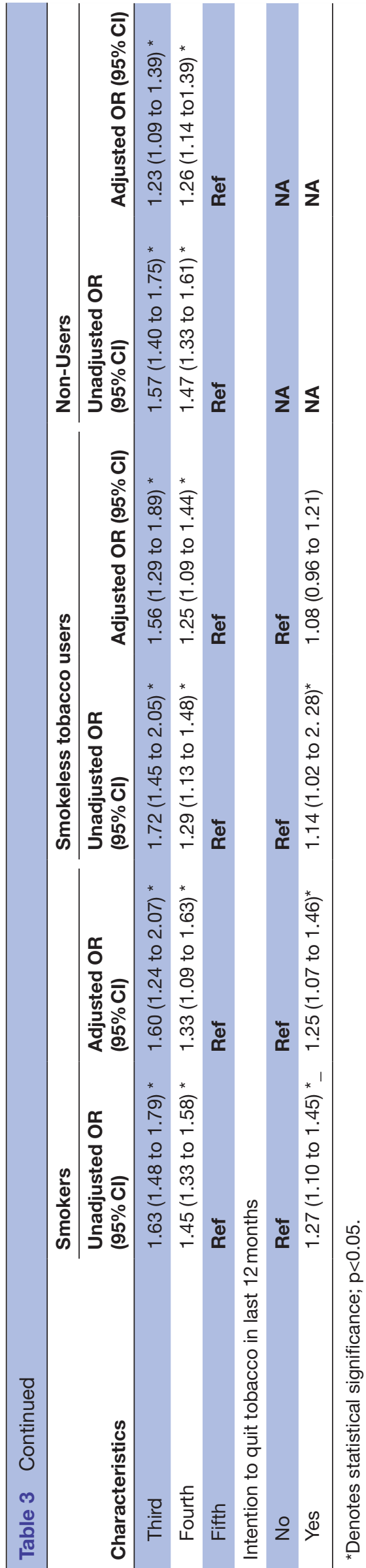

specific pharmacotherapeutic and psychosocial interventions to help quit for those seeking help. We should adopt a continuum of care to reduce tobacco use among people who intend to quit. ${ }^{35}$

Awareness is pivotal to behaviour change and is the cornerstone of tobacco control initiatives. We observed higher awareness among those who had positive intentions to quit tobacco usage. Adequate awareness determines the efficacy of and access to cessation initiatives, quitting rates, compliance with the antitobacco legislation being implemented across the countries. ${ }^{36}$ Therefore, the present study underlines the urgent need to improve knowledge on the dangers of active and passive smoking among socially disadvantaged populations. Policymakers can use this information for developing media and educational and interventional campaigns for specific population subgroups.

There are specific strengths and limitations of the study. The major strength was using the scoring system to assess the comprehensive awareness among users and non-users of tobacco. It is because we expect that inaccurate awareness of tobacco's harmful effects influences users and non-users alike. We were able to track the trends in awareness levels over the two rounds of GATS, which can help us understand the effectiveness of various health promotion activities initiated during the period between at population levels only. However, the cross-sectional nature of data collection couldn't assess the temporality between intention to quit tobacco and awareness. This study was limited only to adult smokers over 15 years old, so responses might not explain the point of generation of awareness of possible health effects of tobacco use. Also, as there was a difference in the number of questions included in the survey to assess awareness about the harmful effect of tobacco, and hence for comparison of awareness, only common variables were studied.

There are specific policy implications of this investigation. Global research has reiterated that there is no safe form of tobacco, including SLT, which contains at least 70 harmful chemicals that cause cancer. ${ }^{37}$ Even with such demonstrable and proven adverse effects, India's widespread use is not surprising because of the addictive properties of tobacco. Those who get addicted and dependent require motivation and sustained efforts to get rid of this habit. Hence, a high level of awareness and health education is needed to encourage people to give up this habit and, more importantly, discourage others from falling into its addictive trap.

\section{CONCLUSIONS AND RECOMMENDATIONS}

Our study findings suggest that awareness regarding the harmful effects of tobacco is lacking among the users and is less than the non-users. It further highlights the need to include strategies for deeper penetration of health promotion activities and bringing the desired behaviour change. Future research can focus on assessing the effectiveness of various health promotion activities and comparing them 
Table 4 Awareness regarding adverse effects due to smoking or smokeless tobacco: a comparison between the two rounds of Global Adults Tobacco Survey (GATS) (India)

\begin{tabular}{|c|c|c|c|c|c|c|c|c|c|}
\hline Characteristics & \multicolumn{3}{|c|}{$\begin{array}{l}\text { Smokers who were aware that } \\
\text { smoking has adverse effects }\end{array}$} & \multicolumn{3}{|c|}{$\begin{array}{l}\text { Smokeless tobacco users who were aware } \\
\text { that smoking has adverse effects }\end{array}$} & \multicolumn{3}{|c|}{$\begin{array}{l}\text { Non-users who were aware that smoking has } \\
\text { adverse effects }\end{array}$} \\
\hline Total & $4930(38 \%)$ & $\begin{array}{l}5826 \\
(60.2 \%)\end{array}$ & 55.95 & 6961 (38.9\%) & $8933(57.2 \%)$ & 47.04 & 44967 (64.9\%) & $35818(66.5 \%)$ & 2.46 \\
\hline \multicolumn{10}{|l|}{ Gender } \\
\hline Female & 32.4 & 43.0 & 32.72 & 36.1 & 50.6 & 40.17 & 44.7 & 64.7 & 44.74 \\
\hline \multicolumn{10}{|l|}{ Age group (years) } \\
\hline $15-29$ & 40.3 & 63.2 & 56.82 & 41.1 & 57.8 & 40.63 & 48.2 & 67.1 & 39.21 \\
\hline $30-44$ & 39.5 & 62.1 & 57.22 & 40.4 & 58.9 & 45.79 & 46.2 & 68.5 & 48.27 \\
\hline $45-59$ & 36.1 & 60.7 & 68.14 & 36.9 & 59.1 & 60.16 & 45.3 & 66.6 & 47.02 \\
\hline Rural & 35.1 & 58.4 & 66.38 & 37.6 & 56.8 & 51.06 & 44.1 & 64.3 & 45.80 \\
\hline \multicolumn{10}{|l|}{ Region } \\
\hline North & 39.3 & 64.1 & 63.10 & 46.2 & 58.6 & 26.84 & 61.3 & 71.2 & 16.15 \\
\hline Central & 38.5 & 56.4 & 46.49 & 42.9 & 57.5 & 34.03 & 47.7 & 63.8 & 33.75 \\
\hline East & 44.9 & 66.9 & 49.00 & 39.3 & 58.0 & 47.58 & 48.7 & 63.4 & 30.18 \\
\hline North East & 50.4 & 53.8 & 6.75 & 48.4 & 53.6 & 10.74 & 51.1 & 54.3 & 6.26 \\
\hline West & 26.0 & 54.4 & 109.23 & 29.9 & 66.1 & 121.07 & 35.4 & 71.5 & 101.98 \\
\hline South & 31.1 & 61.5 & 97.75 & 31.4 & 46.2 & 47.13 & 46.0 & 68.3 & 48.48 \\
\hline
\end{tabular}

Only five questions were common to both rounds. Therefore, we have included only those questions to compare changes across two rounds of GATS.

between tobacco users and non-users and among different sociodemographic variables. We recommend that these campaigns be customised to counter the regional disparities and adopt a gender-neutral approach. Communitybased approaches involving stakeholders like village elderly, healthcare frontline workers and allied community workers leading to the inclusion of the bottom of the pyramid will help in practical and widespread Dissemination. Awareness activities should be started during adolescence as it is a critical period to adopt a healthy lifestyle

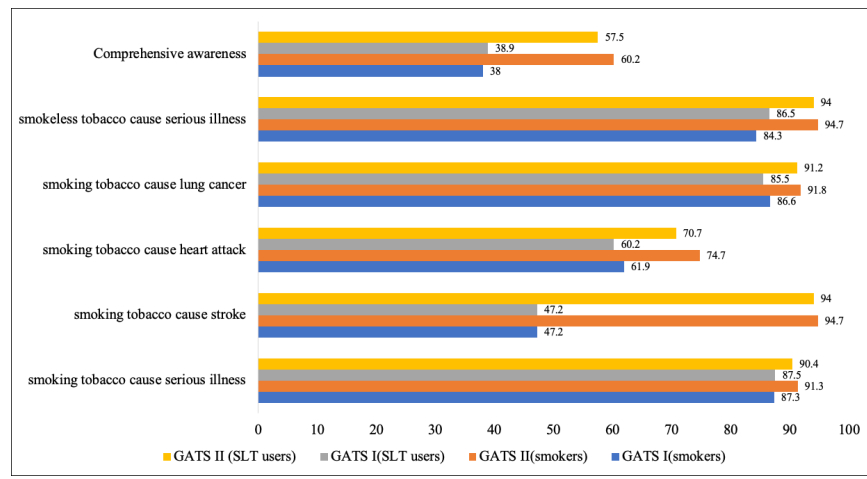

Figure 1 Awareness among the smokers and smokeless tobacco users regarding specific illnesses caused by tobacco consumption in two rounds of Global Adults Tobacco Survey (GATS) (India). and be aware of the harmful effects of tobacco. Lastly, a public health approach that integrates with the existing sociocultural milieu and a supportive environment can be emphasised on from a policy point of view.

\section{Twitter Madhur Verma @drmadhurverma}

Contributors AK: conceptualised the study, acquisition of data, developed analytical framework, analysed the data, interpreted the results, wrote the first draft of the manuscript. SSS: interpreted local policy implications of the results and reviewed, approved the early and advanced drafts of the manuscript. MV led the manuscript preparation and the submission process, developed an analytical framework, interpreted the results, gave critical inputs on multiple draft of the manuscript and revised the manuscript.

Funding The authors have not declared a specific grant for this research from any funding agency in the public, commercial or not-for-profit sectors.

Competing interests None declared.

Patient consent for publication Not required.

Provenance and peer review Not commissioned; externally peer reviewed.

Data availability statement Data are available in a public, open access repository. Data are available in the public domain from the Global Tobacco Surveillance System Data (GTSS Data) maintained by the Centers for Disease Control and Prevention https://nccd.cdc.gov/GTSSDataSurveyResources/Ancillary/DataReports. aspx?CAID $=2$ and freely available to all researchers

Supplemental material This content has been supplied by the author(s). It has not been vetted by BMJ Publishing Group Limited (BMJ) and may not have been peer-reviewed. Any opinions or recommendations discussed are solely those of the author(s) and are not endorsed by BMJ. BMJ disclaims all liability and responsibility arising from any reliance placed on the content. Where the content includes any translated material, BMJ does not warrant the accuracy and reliability 
of the translations (including but not limited to local regulations, clinical guidelines, terminology, drug names and drug dosages), and is not responsible for any error and/or omissions arising from translation and adaptation or otherwise.

Open access This is an open access article distributed in accordance with the Creative Commons Attribution Non Commercial (CC BY-NC 4.0) license, which permits others to distribute, remix, adapt, build upon this work non-commercially, and license their derivative works on different terms, provided the original work is properly cited, appropriate credit is given, any changes made indicated, and the use is non-commercial. See: http://creativecommons.org/licenses/by-nc/4.0/.

\section{ORCID iD}

Madhur Verma http://orcid.org/0000-0002-1787-8392

\section{REFERENCES}

1 Munzer A. The who FCTC: the challenge of implementation. Lancet Respir Med 2013;1:182-4.

2 World Health Organization. Tobacco. facts sheet, 2019. Available: https://www.who.int/en/news-room/fact-sheets/detail/tobacco [Accessed 19 Apr 2020].

3 Owusu-Dabo E, Lewis S, McNeill A, et al. Support for smoke-free policy, and awareness of tobacco health effects and use of smoking cessation therapy in a developing country. BMC Public Health 2011;11:572.

4 Guindon G, Past BD. Current and future trends in tobacco use. Econ. Tob. Control Pap. No 2003;6 https://openknowledge.worldbank.org/ bitstream/handle/10986/13726/292650Guindon1Past10current1 Owhole.pdf?sequence $=1$ \&isAllowed $=y$

5 Ghose S, Sardar A, Shiva S, et al. Perception of tobacco use in young adults in urban India: a qualitative exploration with relevant health policy analysis. Ecancermedicalscience 2019;13:915

6 Schwartz WHL, Samet JM. World No Tobacco Day 2011: India's progress in implementing the framework convention on tobacco control. Indian J Med Res 2020;133:455.

7 National centre for disease informatics and research. National cancer registry program, 2020. Available: https://ncdirindia.org/NCRP/ Annual_Reports.aspx [Accessed 5 Jun 2020].

8 World Health Organization. Tobacco. facts sheet, 2018. Available: https://www.who.int/news-room/fact-sheets/detail/tobacco [Accessed 2 May 2019].

9 Singh A, Ladusingh L. Prevalence and determinants of tobacco use in India: evidence from recent global adult tobacco survey data. PLoS One 2014;9:e114073.

10 Siddiqi K, Shah S, Abbas SM, et al. Global burden of disease due to smokeless tobacco consumption in adults: analysis of data from 113 countries. BMC Med 2015;13:194.

11 World health Organisation. Policy recommendations for smoking cessation and treatment of tobacco dependence. Tob. Free Initiat 2010.

12 Ministry of Health \& Family Welfare Government of India. Global adult tobacco Surey 2016-2017. Int. Inst. Popul. Sci 2017 https://mohfw. gov.in/sites/default/files/GlobaltobacoJune2018.pdf

13 Cheng HG, McBride O, Phillips MR. Relationship between knowledge about the harms of smoking and smoking status in the 2010 global adult tobacco China survey. Tob Control 2015;24:54-61.

14 Milcarz M, Polanska K, Bak-Romaniszyn L, et al. Tobacco health risk awareness among socially disadvantaged People-A crucial tool for smoking cessation. Int J Environ Res Public Health 2018;15:2244.

15 Bryant J, Bonevski B, Paul C. A survey of smoking prevalence and interest in quitting among social and community service organisation clients in Australia: a unique opportunity for reaching the disadvantaged. BMC Public Health 2011;11:827.

16 Driezen P, Abdullah AS, Nargis N, et al. Awareness of tobaccorelated health harms among vulnerable populations in Bangladesh: findings from the International tobacco control (ITC) Bangladesh survey. Int J Environ Res Public Health 2016;13:848.
17 Chiosi JJ, Andes L, Asma S, et al. Warning about the harms of tobacco use in 22 countries: findings from a cross-sectional household survey. Tob Control 2016;25:393-401.

18 ThiMinhAn D, Van Minh H, Thi Huong L. The Vietnam Steering Committee on smoking and health. 2. 3. Hanoi, Vietnam: World Health Organization Office in Viet Nam, 2017.

19 Demaio AR, Nehme J, Otgontuya D, et al. Tobacco smoking in Mongolia: findings of a national knowledge, attitudes and practices study. BMC Public Health 2014;14:213.

20 Sansone GC, Raute LJ, Fong GT, et al. Knowledge of health effects and intentions to quit among smokers in India: findings from the tobacco control policy (TCP) India pilot survey. Int J Environ Res Public Health 2012;9:564-78.

21 Raute LJ, Sansone GC, Pednekar MS. Knowledge of health effects and intentions to quit among smokers in India: findings from the tobacco control policy (TCP) India pilot survey. Asian Pacific J Cancer Prev 2011;12:1233-8.

22 Verma M, Kathirvel S, Das M, et al. Trends and patterns of secondhand smoke exposure amongst the non-smokers in India-A secondary data analysis from the Global Adult Tobacco Survey (GATS) I \& II. PLoS One 2020;15:e0233861.

23 Ministry of Health and Family Welfare; Government of India. Global adult tobacco survey; GATS India- 2009-2010. Int. Inst. Popul. Sci, 2010: 1-289.

24 International Institute for Population Sciences (IIPS). GATS I-Public use data file; codebook. Glob. adult Tob. Surv 2011:82 https://nada. searo.who.int/index.php/catalog/55/download/374

25 International Institute of Population Sciences (IIPS). GATS-2- public use data file; codebook. Glob. adult Tob. Surv 2018:102 https://nada. searo.who.int/index.php/catalog/73

26 Tripathy JP, Verma M. Impact of health warning labels on cigarette packs in India: findings from the global adult tobacco survey 2016-17. Behav Med 2020;0:1-10.

27 Milcarz M, Polanska K, Bak-Romaniszyn L, et al. Tobacco health risk awareness among socially disadvantaged people-A crucial tool for smoking cessation. Int J Environ Res Public Health 2018;15:113.

28 Gupta B, Kumar N. A Cross-Country comparison of knowledge, attitudes and practices about tobacco use: findings from the global adult tobacco survey. Asian Pacific Journal of Cancer Prevention 2014;15:5035-42.

29 Chinwong D, Mookmanee N, Chongpornchai J. A comparison of gender differences in smoking behaviors. Intention to Quit, and Nicotine Dependence among Thai University Students, 2018.

30 Dawood OT, Rashan MAA, Hassali MA, et al. Knowledge and perception about health risks of cigarette smoking among Iraq smokers. J Pharm Bioallied Sci 2016:8:146-51.

31 Lam TH, Li ZB, Ho SY, et al. Smoking, quitting and mortality in an elderly cohort of 56,000 Hong Kong Chinese. Tob Control 2007;16:182-9.

32 Gilman SE, Martin LT, Abrams DB, et al. Educational attainment and cigarette smoking: a causal association? Int J Epidemiol 2008;37:615-24.

33 Sharma D, Goel S, Lal P. Education differential in relation to tobacco use and its predictors across different regions of India. Indian $J$ Cancer 2017;54:584-8.

34 Pärna K, Pürjer M-L, Ringmets I, et al. Educational differences in cigarette smoking among adult population in Estonia, 1990-2010: does the trend fit the model of tobacco epidemic? BMC Public Health 2014;14:709.

35 Giri PP, Tripathy D, Sahoo SS. Prevalence and correlates of substance use in rural Bhubaneswar - a community based cross sectional study. Indian J Community Heal 2019;31:90-6.

36 Viswanath K, Herbst RS, Land SR, et al. Tobacco and cancer: an American association for cancer research policy statement. Cancer Res 2010;70:3419-30.

37 American Cancer Society. Harmful chemicals in tobacco products. Tob. Cancer 2020 https://www.cancer.org/cancer/cancer-causes/ tobacco-and-cancer/carcinogens-found-in-tobacco-products.html 